\title{
STRUCTURAL RELIABILITY OF PRE-STRESSED CONCRETE CONTAINMENTS
}

\author{
Nawal K Prinja ${ }^{1}$, Azeezat Ogunbadejo ${ }^{2}$, Jonathan Sadeghi ${ }^{3}$ and Edoardo Patelli ${ }^{4}$ \\ ${ }^{1}$ Technical Director, Clean Energy, AMEC Foster Wheeler, Booths Park, Knutsford, Cheshire WA16 \\ 8QZ, UK \\ ${ }^{2}$ MSc student, School of Eng., University of Aberdeen \\ ${ }^{3} \mathrm{PhD}$ student, Institute for Risk and Uncertainty, University of Liverpool \\ ${ }^{4}$ Lecturer, Institute for Risk and Uncertainty, University of Liverpool \\ E-mail of corresponding author: nawal.prinja@amecfw.com
}

\begin{abstract}
This paper presents probabilistic analysis of structural capacity of pre-stressed concrete containments subjected to internal pressure. The conventional design methods for containments are based on allowable stress codes which ensure certain factor of safety between expected load and expected structural strength. Such an approach may give different values of structural reliability in different situations. In recent years, two international round robin exercises have been conducted aimed at predicting the capacity of lined and unlined pre-stressed concrete containments used in nuclear industry. These exercises involved experimental testing and numerical analysis of the models. The first exercise involved $1 / 4$ scale steel-lined Pre-stressed Concrete Containment Vessel (PCCV) which was tested at Sandia National Laboratories (SNL) in USA. The second used an unlined containment being tested by the Bhabha Atomic Research Centre (BARC), Tarapur, India. These studies are essentially deterministic studies that have helped validate the analysis methodology and modelling techniques that can be used to predict pre-stressed concrete containment capacity and failure modes. The paper uses these two examples to apply structural reliability method to estimate the probability of failure of the containment.
\end{abstract}

The two international round robin exercises have already established the ultimate structural collapse mode of the containments under internal pressure loading which indicate that the failure takes place in the general field of the containment wall around mid-height and away from any major structural discontinuities like the penetrations. This is because robust design procedures have been used to avoid structural failure at discontinuities by providing adequate compensation. Based on these experimental studies and the attendant numerical analyses a failure function is presented that assumes first yielding in the hoop direction at mid-height of the cylinder wall. A failure function equating the free-field membrane hoop stress to the hoop strength as a function of cross-sectional area (per unit height) and yield stresses of concrete, rebar, liner plate and tendons is developed.

First Order Reliability Method (FORM) is applied to predict probability of failure of the containments. Probability of failure vs internal pressure is presented for both types of containments. The paper presents a simple method to establish structural reliability of a pre-stressed concrete containment which can be useful for probabilistic safety assessment when considering extreme events that lead to overpressurisation of the containment. The FORM approach was validated by comparison to the results of analogous calculations using Subset Simulation and Importance Sampling techniques for Monte Carlo simulation. It was found that at high pressures the Advanced FORM approach yields a good approximation to the true probability of failure.

The sensitivity of the probability of failure to the assumed coefficients of variation of properties of the containment was studied using the Sobol and Total Effects Indices. At design pressure it was found that the coefficients of variation of the tendon yield and tendon area are the most important parameters followed by the applied pressure and containment radius. At higher pressures it was found that the 
coefficients of variation of the applied pressure and containment radius are the most important parameters. The variability of the probability of failure is decreased at higher pressures, but the coefficients of variation still play an important role.

\section{KEYWORDS}

Concrete containment, structural reliability, containment capacity, probabilistic safety assessment, fragility, sensitivity analysis, coefficient of variation.

\section{INTRODUCTION}

A pre-stressed concrete containment is an important safety related structure as it acts as one of the final barriers to radioactive release. These structures are normally designed in accordance with the allowable stress codes to sustain the specified loading conditions. However, the compliance with the industry standard allowable stress codes does not give any reliable indication of the probability of failure $\left(\mathrm{P}_{\mathrm{f}}\right)$ if the containment is over-pressurised under postulated beyond design basis events. In the past few years, two international round robin exercises have been conducted which have provided valuable test data related to failure under over-pressurisation. The first exercise involved the numerical analysis of the $1 / 4$ scale steellined Pre-stressed Concrete Containment Vessel (PCCV) with design pressure (Pd) of 0.39MPa which was tested at Sandia National Laboratories (SNL) in USA and has been analysed by Prinja and Shepherd (2003). The second exercise involved the unlined Bhabha Atomic Research Centre (BARC) Containment test model (BARCOM) with Pd of 0.1413 MPa that is being tested by the BARC in Tarapur, India and has been analysed by Kamatam and Prinja (2011). These studies are essentially deterministic studies that have helped validate the analysis methodology and modelling techniques that can be used to predict prestressed concrete containment capacity and failure modes. Such deterministic analytical and experimental studies have helped to establish the mode of failure but do not give any indication of $\mathrm{P}_{\mathrm{f}}$. Furthermore, the conventional allowable stress codes used to design such containments also do not provide $\mathrm{P}_{\mathrm{f}}$ information. The aim of this paper is to present a simple method to establish structural reliability of a pre-stressed concrete containment which can be useful for probabilistic safety assessment when considering overpressurisation under extreme events.

The method used to perform the analysis was Advanced FORM, a computationally efficient approximate method. In addition, Sensitivity Analysis was used in order to justify some arbitrary parameters used in the structural reliability analysis. Sensitivity Analysis is the process of attributing the uncertainty in the output of a mathematical model to the different sources of uncertainty in its inputs. In this paper we determine the sensitivity of the probability of failure of a concrete containment vessel to the assumed coefficients of variation of input parameters to the structural reliability analysis. These input parameters are physical properties of the containment. Before the sensitivity analysis was completed, the FORM method was validated for the containment at the design pressure and at 5.4 times the design pressure to provide an indication of the credibility of the FORM. This calculation was performed by comparing the results from the FORM to the true value of the probability of failure obtained from Subset Simulation and Importance Sampling as it was found that the failure probability was too small to be evaluated in a short time using standard Monte Carlo simulation. Once this was completed the parameters whose variance had the greatest contribution to the variance of the output were determined using the Sobol and Total Effects indices, and the effect on $\mathrm{P}_{\mathrm{f}}$ of varying these parameters was considered in greater detail.

\section{FAILURE MODE}

Both SNL and BARCOM tests have shown that the collapse of the containment structure subjected to internal pressure is not expected to occur soon after the design pressure is exceeded. There is no 'cliff edge' but a gradual progressive damage of the containment structure under over-pressurisation which 
indicates safety margin against collapse. The structure may suffer local failures leading to functional failure well before the ultimate structural collapse. The experiments and the attendant numerical analyses have established the ultimate structural collapse mode of the containments under internal pressure loading which indicates that the failure takes place in the general field of the containment wall around mid-height and away from any major structural discontinuities like the penetrations. This is because robust design procedures have been used that provide adequate compensation and local strengthening to avoid structural failure at discontinuities. Based on these experimental studies and the attendant numerical analyses a failure function is presented that assumes first yielding in the hoop direction at mid-height of the cylinder wall.

In the case of the SNL model shown in Figure 1, the failure location at applied pressure (P) of 3.65 Pd was accurately predicted by the computational model at mid-height of the cylinder in the general area away from the buttress and main penetrations. The BARCOM model is also predicted to fail at midheight of the cylinder wall as indicated in the deformed shape shown in Figure 2.

Load-deflection curve obtained from the test is compared against that predicted by analysis for the SNL model in Figure 3 at location 14 near the failure location. Note that in the test the internal pressure is released soon after the break but in the analysis the pressure is maintained. The SNL model failed at $\mathrm{P} / \mathrm{Pd}=3.65$ in test and was predicted to fail at $\mathrm{P} / \mathrm{Pd}=3.35$ in the analysis.

\section{FAILURE FUNCTION}

Failure of a containment structure is dictated by the strain levels experienced by the tendons, rebars and the liner following the tensile cracking of the concrete. The first membrane yield is expected to occur in the

hoop direction in the cylinder wall. If the failure state is defined as the tensile cracking of the concrete and yielding of the tendons, rebars and the liner, then the internal pressure at a specific deformed shape is given by:

$$
P=\frac{1}{R}\left(\left(A_{s} * F_{S}+A_{c} * F_{c}+A_{l} * F_{l}+A_{t} * F_{t}\right)\right.
$$

Where $A_{s}, A_{c}, A_{l}, A_{t}$ are cross-sectional areas of the rebar steel, concrete, liner plate and tendons respectively given as area per unit height of the cylinder wall. $F_{s}, F_{1}$ and $F_{t}$ are yield stress of rebar steel, liner plate and tendons respectively and $\mathrm{F}_{\mathrm{c}}$ is the tensile strength of the concrete. $\mathrm{R}$ is the mid-radius of the cylinder wall.

The failure function ' $\mathrm{g}$ ' can be written as:

$$
g=P R-\left(A_{s} * F_{s}+A_{c} * F_{c}+A_{l} * F_{l}+A_{t} * F_{t}\right)
$$

\section{FORM Analysis}

If $\mathrm{Z}$ is a function of many basic variables then $\mathrm{Z}=\mathrm{g}\left(\mathrm{x}_{1}, \mathrm{x}_{2}, \ldots \ldots \mathrm{x}_{\mathrm{n}}\right)=0$ can be written using Taylor series as:

$$
Z=g\left(x_{1}^{*}, x_{2}^{*}, \ldots x_{n}^{*}\right)+\sum_{i=1}^{i=n}\left(x_{i}-x_{i}^{*}\right) g_{i}^{\prime}\left(x^{*}\right)+\ldots
$$

where $g_{i}^{\prime}\left(x^{*}\right)$ is derivative $\frac{\partial g}{\partial x_{i}}$ evaluated at $x_{i}=x_{i}^{*}$ 


$$
Z=k_{0}+\sum_{i=1}^{i=n} k_{i} x_{i}
$$

The mean $\mu_{Z}$ and standard deviation $\sigma_{Z}$ of $Z$ are given as:

$$
\begin{aligned}
& \mu_{Z}=k_{0}+\sum_{i=1}^{i=n} k_{i} m_{i} \\
& \sigma_{Z}=\left[\sum_{i=1}^{i=n} k_{i}^{2} \sigma_{i}^{2}\right]^{\frac{1}{2}}
\end{aligned}
$$

The reliability index, $\beta$ is given by

$$
\beta=\frac{\mu_{Z}}{\sigma_{Z}} \quad \text { with probability of failure, } P_{f}=\phi(-\beta) \text { and reliability, } R=1-\phi(-\beta)
$$

where $\phi$ is the standardised cumulative normal distribution.

In structural reliability, eqn (2) can also be written in terms of load (L) and strength (S) terms as follows:

$$
\mathrm{Z}=\mathrm{g}\left(\mathrm{x}_{1}, \mathrm{x}_{2}, \ldots \ldots \mathrm{x}_{\mathrm{n}}\right)=\mathrm{S}-\mathrm{L}
$$

where $\mathrm{S}=\left(A_{s} * F_{S}+A_{c} * F_{c}+A_{l} * F_{l}+A_{t} * F_{t}\right)$ and $\mathrm{L}=\mathrm{PR}$

If $\mu_{\mathrm{S}}$ and $\mu_{\mathrm{L}}$ are mean values and $\mathrm{V}_{\mathrm{S}}$ and $\mathrm{V}_{\mathrm{L}}$ are coefficient of variation $(\mathrm{CoV})$ of the strength and the load terms ( $\mathrm{S}$ and $\mathrm{L}$ ) respectively, then the reliability index, $\beta$ can be written in terms of Central Factor of Safety $(\eta)$ defined as the ratio of the mean values of S and L terms $\left(\eta=\mu_{S} / \mu_{L}\right)$ :

$$
\begin{aligned}
& \beta=\frac{\left(\mu_{S}-\mu_{L}\right)}{\sqrt{\left(\sigma_{S}^{2}+\sigma_{L}^{2}\right)}}=\frac{\left(\frac{\mu_{S}}{\mu_{L}}-1\right)}{\sqrt{\left(\frac{\sigma_{S}}{\mu_{L}}\right)^{2}+\left(\frac{\sigma_{L}}{\mu_{L}}\right)^{2}}}=\frac{\left(\frac{\mu_{S}}{\mu_{L}}-1\right)}{\sqrt{\left(\frac{\sigma_{S}}{\mu_{S}}\right)^{2}\left(\frac{\mu_{S}}{\mu_{L}}\right)^{2}+\left(\frac{\sigma_{L}}{\mu_{L}}\right)^{2}}} \\
& \beta=\frac{(\eta-1)}{\sqrt{\left(V_{S}^{2} \eta^{2}+V_{L}^{2}\right)}}
\end{aligned}
$$

The above equation has been used to obtain $\mathrm{P}_{\mathrm{f}}$ for various values of the Central Factor of Safety assuming that $\mathrm{CoV}$ of both load and strength terms are equal. Figure 4 shows the $\mathrm{P}_{\mathrm{f}} \mathrm{vs} \eta$ plots for $\mathrm{CoV}$ of 0.1 and 0.2 . It can be seen that when $\mathrm{V}_{\mathrm{S}}=\mathrm{V}_{\mathrm{L}}$, the probability of failure is $50 \%$ when the load term equals the strength term.

\section{Advanced FORM Analysis}

The failure function of the containment structure given in eqn (2) has ten variables. When all ten variables are used, the failure function becomes nonlinear and advanced FORM analysis is used following the iterative algorithm recommend by Rackwitz (1976):-

1. Guess an initial value of $\beta$ typically starting with $\beta=3$

2. Set $x_{i}{ }^{*}=\mu_{i}$ for all $i$. All variables set to their respective mean value $\mu$ at the start. 
3. Compute partial derivative of $\frac{\partial g}{\partial x_{i}}$ also known as $\mathrm{a}_{\mathrm{i}}$ for all $\mathrm{i}$ at $x=x^{*}$

4. Compute Sensitivity factors, $\propto_{i}=\frac{a_{i} * \sigma_{i}}{\left(\sqrt{\sum_{j=1}^{j=n}\left(a_{j} * \sigma_{j}\right)^{2}}\right.}$

5. Compute new $x^{*}$ values using $x_{i}{ }^{*}=\mu_{i}-\left(\alpha_{i} \beta \sigma_{i}\right)$

6. Repeat step 3 to 5 to get stable values of all $x^{*}$

7. Evaluate $z=g\left(x_{1}^{*}, x_{2}^{*}, \ldots \ldots, x_{n}^{*}\right)$

8. Evaluate $\frac{d Z}{d \beta}$ using $\frac{d Z}{d \beta}=\sum-a_{i} * \propto_{i} * \sigma_{i}$

9. $\beta_{\text {new }}=\beta_{\text {old }}-Z_{n} / \frac{d Z}{d \beta}$

10. Compute modified design values $x_{i}{ }^{*}=\mu_{i}-\left(\alpha_{i} \beta \sigma_{i}\right)$

11. Repeat steps 3 to 11 till stable value of $\beta$ is achieved.

12. Calculate probability of failure, $P_{f}=\varphi(-\beta)$

\section{PROBABILITY OF FAILURE CALCULATIONS}

The cross-sectional area properties were obtained from the geometric data as follows:-

Steel rebar area/unit height, $\mathrm{A}_{\mathrm{s}}=\mathrm{n}_{\mathrm{s}} * \pi * \mathrm{r}_{\mathrm{s}}^{2} / \mathrm{h}_{\mathrm{s}}$

Where $\mathrm{n}_{\mathrm{s}}=$ number of steel rebars through wall thickness

$r_{s}$ is radius of steel rebar and $h_{s}$ is the vertical spacing.

Liner area/unit height, $A_{l}=$ thicknessof the plate $\mathrm{x} 1$

Tendon area/unit height, $A_{t}=n_{t} * \pi * r_{t}^{2} / h_{t}$

Where $\mathrm{n}_{\mathrm{t}}=$ number of tendons through wall thickness. $\mathrm{r}_{\mathrm{t}}$ is tendon radius and $\mathrm{h}_{\mathrm{t}}$ is tendon vertical spacing.

Concrete area/unit height, $A_{c}=\left(\left(r_{o}-r_{i}\right)-\left(A_{1}+A_{s}+A_{t}\right)\right)$

$r_{o}$ and $r_{i}$ are outer and inner radii of the wall and mid-radius of the wall, $R=\left(r_{o}+r_{i}\right) / 2$.

\section{SNL Containment Data}

In the SNL model, each tendon is built from 3 wires of $13.7 \mathrm{~mm}$ diameter so and there were 90 hoop tendons in the wall height of $10750 \mathrm{~mm}$ giving tendon vertical spacing, $\mathrm{h}_{\mathrm{t}}=119.4 \mathrm{~mm}$.

With $\mathrm{n}_{\mathrm{t}}=3$ and $\mathrm{r}_{\mathrm{t}}=6.85 \mathrm{~mm}$

$A_{t}=(3 * 3.14 * 6.85 * 6.85) / 119.4=3.70 \mathrm{~mm}^{2} / \mathrm{mm}$

There are two hoop rebars (inner and outer) of $22.2 \mathrm{~mm}$ dia which are vertically spaced at $113 \mathrm{~mm}$ interval. With $\mathrm{n}_{\mathrm{s}}=2$ and $\mathrm{r}_{\mathrm{s}}=11.1 \mathrm{~mm}$

$\mathrm{A}_{\mathrm{s}}=(2 * 3.142 * 11.1 * 11.1) / 113=6.85 \mathrm{~mm}^{2} / \mathrm{mm}$

$A_{1}=$ thickness of the plate $x 1=1.6 \mathrm{~mm}^{2} / \mathrm{mm}$

$\mathrm{A}_{\mathrm{c}}=312.85 \mathrm{~mm}^{2} / \mathrm{mm}$

Where $r_{o}=5700 \mathrm{~mm}, r_{i}=5375 \mathrm{~mm}$ and $\mathrm{R}=5537.5 \mathrm{~mm}$ 


\section{BARCOM Containment Data}

The BARCOM model has no liner so $A_{1}=0$. In the area of failure there are two steel rebars of $12 \mathrm{~mm}$ dia used as hoop reinforcement through the thickness of the wall at intervals of $200 \mathrm{~mm}$. Therefore, $\mathrm{A}_{\mathrm{s}}=(2 * 3.14 * 6 * 6) / 200=1.1304 \mathrm{~mm}^{2} / \mathrm{mm}$

One $24 \mathrm{~mm}$ dia hoop tendon (horizontal cable) is placed at vertical interval of $110 \mathrm{~mm}$ giving $\mathrm{A}_{\mathrm{t}}=4.11 \mathrm{~mm}^{2} / \mathrm{mm}$. The wall is $188 \mathrm{~mm}$ thick and goes from elevation level $-2.25 \mathrm{~m}$ to $+9.025 \mathrm{~m}$ giving wall height of $11275 \mathrm{~mm}$.

$\mathrm{r}_{\mathrm{o}}=6376 \mathrm{~mm}, \mathrm{r}_{\mathrm{i}}=6188 \mathrm{~mm}$ and $\mathrm{R}=6282 \mathrm{~mm}$.

Therefore, $\mathrm{A}_{\mathrm{c}}=182.76 \mathrm{~mm}^{2} / \mathrm{mm}$.

The geometric data is summarised in table 1 .

The applied internal pressure $(\mathrm{P})$ is increased from $0 \mathrm{MPa}$ till probability of failure $\left(\mathrm{P}_{\mathrm{f}}\right)$ of 1.0 is achieved.

\section{Statistical Data for Material and Geometry}

In structural reliability analysis for concrete containment capacities, tensile strength of two different types of materials need to be considered: concrete and steel. Concrete behaves like a brittle material whereas steel components like the tendons, rebars and liner plate will exhibit plastic behaviour when loaded beyond their yield stress. In case of concrete, variability in strength can be traced to two fundamentally different sources: variability in the properties of the concrete mixture and ingredients and variability in the way the strength is tested and measured. Similarly variability in yield strength of a given steel varies due to variation in chemistry, heat treatment and mechanical processing. Typically, it is the compressive strength concrete which is specified and measured. The tensile strength of concrete is taken to be about $10 \%$ of its compressive strength at room temperature. At higher temperatures, the strength tends to decrease and any loss in the tensile strength is proportional to the corresponding loss in the compressive strength.

Variability in geometric dimensions of engineered components depends on the manufacturing process and the specified tolerances. Usually tolerances in manufacturing processes are tight and tend to follow normal distribution.

In this example, all material, geometric and loading parameters are assumed to have $\mathrm{CoV}$ of 0.2 with normal distribution. In practice, the $\mathrm{CoV}$ in yield strength of steel components could be less than 0.1 and the $\mathrm{CoV}$ of geometric dimensions could be even lower.

Mean values and coefficient of variation used for strength and loading variables are given in table 2.

\section{Results}

Figure 5 presents $\mathrm{P} / \mathrm{Pd}$ vs $\mathrm{P}_{\mathrm{f}}$ curves for both SNL and BARCOM models obtained by using the advanced FORM analysis. Two curves for each model are presented. One in which all ten variables were considered and the other in which the concrete was assumed to be totally damaged due to previous testing and was assigned zero strength. Similar sensitivity exercises can be conducted to study the influence of variation in material, loading and geometric parameters. Failure curves of the kind depicted in Figure 5 can be used to define the fragility of concrete containments under over-pressure. 


\section{DISCUSSION AND CONCLUSIONS}

The available test data and the FEA results (Kamatam \& Prinja (2011) and Prinja \& Shepherd (2003)) showed that the structural response of the pressurised PCCV is indicated by progressive damage in three stages. The first stage up to the design pressure $(\mathrm{P} / \mathrm{Pd}=1)$ is predominantly elastic response and can be predicted with very good accuracy. The second stage involving inelastic response with extensive concrete cracking with local yielding or rupture may lead to loss of functionality (leakage) or breach of pressure boundary. The third stage involves gross deformation leading to the structural collapse. The $\mathrm{P}_{\mathrm{f}}$ of this gross structural collapse depends on the amount of steel and concrete used in the design as given in equation 1 . The strength terms (given by area $\mathrm{x}$ yield stress) for rebar, liner, tendon and concrete are compared in Table 3 for the SNL and BARCOM models along with the design load term (given by Pd $\mathrm{x}$ mid-radius of the wall). It can be seen that whilst the overall strength of the two containment models is almost similar, the load term of the BARCOM model is only $40 \%$ of the SNL model. The strength/load ratio $(\gamma)$ for the SNL is 5.4 but for the BARCOM model it is 9.7 so overall the BARCOM model is nearly twice as strong as the SNL model. This is reflected in the $\mathrm{P}_{\mathrm{f}} \mathrm{vs} \mathrm{P} / \mathrm{Pd}$ curves presented in Fig 5. In case of the SNL model, the load term equals the strength term when $\mathrm{P}=5.4 \mathrm{Pd}$ but for the BARCOM model it is when $\mathrm{P}=9.7 \mathrm{Pd}$. Therefore, the $\mathrm{P}_{\mathrm{f}}$ for $\mathrm{SNL}$ is $50 \%$ when $\mathrm{P}=5.4 \mathrm{Pd}$ but in the test, the SNL model failed catastrophically at $\mathrm{P}=3.65 \mathrm{Pd}$. Catastrophic failure at pressure lower than $5.4 \mathrm{Pd}$ could be because of extensive damage to the concrete and the liner due to earlier testing. If similar trend is to be followed then the BARCOM model has to be pressurised beyond 9.7Pd. Such pressurisation in a test may not be easily achieved due to problems with localised failures and leakage.

Table 1 Summary of geometric data for the SNL and BARCOM models

\begin{tabular}{|l|r|r|}
\hline Geometric Data & SNL & BARCOM \\
\hline Outside radius of the wall, $\mathrm{r}_{\mathrm{o}}(\mathrm{mm})$ & 5700 & 6376 \\
\hline Inner radius of the wall, $\mathrm{r}_{\mathrm{i}}(\mathrm{mm})$ & 5375 & 6188 \\
\hline Wall thickness $(\mathrm{mm})$ & 325 & 188 \\
\hline Wall height $(\mathrm{mm})$ & 10750 & 11275 \\
\hline Mid-radius, $\mathrm{R}(\mathrm{mm})$ & 5537.5 & 6282 \\
\hline No. of tendons through wall, $\mathrm{n}_{\mathrm{t}}$ & 3 & 1 \\
\hline Tendon vertical spacing, $\mathrm{h}_{\mathrm{t}}(\mathrm{mm})$ & 119.4 & 110 \\
\hline Tendon radius, $\mathrm{r}_{\mathrm{t}}(\mathrm{mm})$ & 6.85 & 12 \\
\hline Tendon area, $\mathrm{A}_{\mathrm{t}}(\mathrm{mm} 2 / \mathrm{mm})$ & 3.70 & 4.11 \\
\hline No. of rebars through wall, $\mathrm{n}_{\mathrm{s}}$ & 2 & 2 \\
\hline Rebar vertical spacing, $\mathrm{h}_{\mathrm{s}}(\mathrm{mm})$ & 113 & 200 \\
\hline Rebar radius, $\mathrm{r}_{\mathrm{s}}(\mathrm{mm})$ & 11.1 & 6 \\
\hline Steel rebar area, $\mathrm{A}_{\mathrm{s}}(\mathrm{mm} 2 / \mathrm{mm})$ & 6.85 & 1.13 \\
\hline Liner plate thickness $(\mathrm{mm})$ & 1.6 & 0 \\
\hline Liner area, $\mathrm{A}_{\mathrm{l}}(\mathrm{mm} 2 / \mathrm{mm})$ & 1.6 & 0 \\
\hline Concrete area, $\mathrm{A}_{\mathrm{c}}(\mathrm{mm} 2 / \mathrm{mm})$ & 312.85 & 182.76 \\
\hline
\end{tabular}


Table 2 Mean values of parameters used for SNL and BARCOM containments

\begin{tabular}{|r|r|r|r|r|}
\hline \multirow{2}{*}{ Load and Strength Data } & \multicolumn{2}{|c|}{ Mean Values $(\boldsymbol{\mu})$} & \multirow{2}{*}{ BARCOM/SNL } & \multirow{2}{*}{ CoV } \\
\cline { 2 - 3 } & \multicolumn{1}{|c|}{ SNL } & BARCOM & & \\
\hline Concrete tensile strength, $\mathrm{F}_{\mathrm{c}}$ & 4.4 & 3.018 & $69 \%$ & 0.2 \\
\hline Liner yield, $\mathrm{F}_{1}$ & 382 & 0 & & 0.2 \\
\hline Rebar Yield, $\mathrm{F}_{\mathrm{s}}$ & 465 & 415 & $89 \%$ & 0.2 \\
\hline Tendon yield, $\mathrm{F}_{\mathrm{t}}$ & 1740 & 1848 & $106 \%$ & 0.2 \\
\hline Design Pressure, $\mathrm{Pd}$ & 0.39 & 0.1413 & & 0.2 \\
\hline Radius, $\mathrm{R}$ & 5537.5 & 6282.0 & $113 \%$ & 0.2 \\
\hline Concrete Area, $\mathrm{A}_{\mathrm{c}}$ & 312.85 & 182.76 & $58 \%$ & 0.2 \\
\hline Liner area, $\mathrm{A}_{\mathrm{l}}$ & 1.6 & 0 & $0 \%$ & 0.2 \\
\hline Rebar Area, $\mathrm{A}_{\mathrm{s}}$ & 6.85 & 1.13 & $17 \%$ & 0.2 \\
\hline Tendon area, $\mathrm{A}_{\mathrm{t}}$ & 3.70 & 4.11 & $111 \%$ & 0.2 \\
\hline
\end{tabular}

Table 3 Relative Strength and Load Terms for SNL and BARCOM containments

\begin{tabular}{|c|c|c|c|}
\hline Strength Term & SNL & BARCOM & BARCOM/SNL \\
\hline Rebar $\left(A_{s} \times F_{s}\right)$ & 3184.1 & 469.1 & 0.1 \\
\hline Liner $\left(A_{l} \times F_{l}\right)$ & 611.2 & 0.0 & 0.0 \\
\hline Tendon $\left(A_{t} \times F_{t}\right)$ & 6439.0 & 7596.3 & 1.2 \\
\hline Concrete $\left(A_{c} \times F_{c}\right)$ & 1376.5 & 551.6 & 0.4 \\
\hline Total Strength term, S & 11610.8 & 8617.0 & 0.7 \\
\hline Design Load Term $(L=$ Pd $\times$ R) & 2159.6 & 887.6 & 0.4 \\
\hline Strength/Load Ratio $(\mathrm{Y})$ & 5.4 & 9.7 & 1.8 \\
\hline
\end{tabular}

\section{SIMPLIFIED METHOD FOR STRUCTURAL RELIABILITY OF CONCRETE CONTAINMENTS}

Assuming that the structural collapse of a containment occurs at the mid-height of the wall, the $\mathrm{P}_{\mathrm{f}}$ of the containment can be estimated using the simplified procedure presented in Fig 6. All that is required is mean values of the five geometric $\left(\mathrm{A}_{s}, \mathrm{~A}_{\mathrm{c}}, \mathrm{A}_{\mathrm{l}}, \mathrm{A}_{\mathrm{t}}\right.$ and $\left.\mathrm{R}\right)$ and four material $(\mathrm{Fs}, \mathrm{Fl}, \mathrm{Ft}$ and $\mathrm{Fc}$ ) variables to establish the strength/design load ratio $(\gamma)$. The $P_{f}=0.5$ when the applied pressure, $P=\gamma$ Pd. $P_{f}$ at other pressures can be obtained by using either the simple FORM (eqn 10) or advanced FORM for which $\mathrm{CoV}$ values for all ten variables are required.

\section{VALIDATION OF ADVANCED FORM}

As advanced FORM is an approximate method, the method will be validated by comparing the obtained $\mathrm{P}_{\mathrm{f}}$ from FORM to the equivalent $\mathrm{P}_{\mathrm{f}}$ from Monte Carlo sampling. As the failure probability when the mean pressure is equal to the design pressure is small, the variance of the estimator of $P_{\mathrm{f}}$ is large. This is because it is difficult to obtain enough samples to sufficiently reduce the variance in a reasonable computational time. Therefore the variance reduction strategies of Subset Simulation and Importance Sampling were used to obtain $\mathrm{P}_{\mathrm{f}}$, and these were compared with the result from Advanced FORM. For both of these algorithms the implementation in the generalized uncertainty quantification software OpenCOSSAN was used (Patelli, 2014 and Patelli, 2016). 
$\mathrm{P}_{\mathrm{f}}$ was also calculated with an increased value of the mean value of $\mathrm{P}, P=5.4 \mathrm{Pd}$, using the advanced FORM and compared to the result from standard Monte Carlo simulation. Standard Monte Carlo simulation was applicable for this calculation because variance reduction strategies are not required when $\mathrm{P}_{\mathrm{f}}$ is large.

The input parameter values assumed in this analysis were taken from the Sandia National Laboratories tests (Table 2), and in order to make a fair comparison it was assumed that the random variables were normally distributed.

\section{IMPORTANCE SAMPLING}

The Monte Carlo estimator of failure probability is given by

$$
P_{f}=\int I_{f}(x) f_{X}(x) d x=\frac{1}{n} \sum_{i=1}^{n} I_{f}\left(x_{i}\right) \text {, }
$$

where $\mathrm{x}_{\mathrm{i}}$ are samples drawn from $\mathrm{f}_{\mathrm{X}}(\mathrm{x})$, the probability density function of the random variables, and $\mathrm{I}_{\mathrm{f}}(\mathrm{x})$ is the indicator function for the failure domain (i.e. $\mathrm{I}_{\mathrm{f}}(\mathrm{x})$ is non-zero only in the failure region given by $\mathrm{g}(\mathrm{x}) \geq 0$ from Equation 2). In Importance Sampling samples are drawn from a distribution with a higher density in the failure region, thereby reducing the variance of the estimator. Therefore the estimator is written as

$$
P_{f}=\int \frac{I_{f}(x) f_{X}(x)}{h(x)} h(x) d x=\frac{1}{n} \sum_{i=1}^{n} \frac{I_{f}\left(x_{i}\right) f_{X}\left(x_{i}\right)}{h\left(x_{i}\right)},
$$

where $\mathrm{x}_{\mathrm{i}}$ are drawn from $\mathrm{h}(\mathrm{x})$. By finding the design point with an approximate method an appropriate $\mathrm{h}(\mathrm{x})$ can be chosen. A more complete discussion of the technique is given in (Schuëller \& Stix, 1987).

\section{SUBSET SIMULATION}

Subset simulation aims to calculate $\mathrm{P}_{\mathrm{f}}$ by decomposing the space of the random variables into several intermediate failure events with decreasing failure probability. The conditional probabilities for the intermediate failure regions can then be used to calculate $\mathrm{P}_{\mathrm{f}}$ which is given by

$$
P_{f}=P\left(F_{m}\right)=P\left(F_{i}\right) \prod_{i=1}^{m-1} P\left(F_{i+1} \mid F_{i}\right),
$$

where $F_{i}$ represents intermediate failure event i. By making the conditional probability of samples falling in the intermediate failure regions large the variance of each individual failure event can be minimised, thereby minimising the variance of $\mathrm{P}_{\mathrm{f}}$. Markov chains are used to generate conditional samples from one failure region to the next in order to calculate $\mathrm{P}\left(\mathrm{F}_{\mathrm{i}+1} \mid \mathrm{F}_{\mathrm{i}}\right)$. A complete description of the method is given in Au \& Beck (2001).

\section{RESULTS}

The probability of failure for the system at design pressure is shown in Table 4. The probability of failure for the system at $P=5.4 P_{d}$ is shown in Table 5 .

Table 4: Probability of failure at $P=P_{d}$ computed by different methods.

\begin{tabular}{|l|l|l|}
\hline Method & $\mathrm{P}_{\mathrm{f}}$ & Variance of $\mathrm{P}_{\mathrm{f}}$ \\
\hline Advanced FORM & $2.7 \times 10^{-8}$ & Not Applicable \\
\hline Subset Simulation & $7.8 \times 10^{-8}$ & $2.4 \times 10^{-9}$ \\
\hline Importance Sampling & $6.7 \times 10^{-8}$ & $1.8 \times 10^{-9}$ \\
\hline
\end{tabular}


Table 5: Probability of failure at $P=5.4 P_{d}$ computed by different methods.

\begin{tabular}{|l|l|l|}
\hline Method & $\mathrm{P}_{\mathrm{f}}$ & Variance of $\mathrm{P}_{\mathrm{f}}$ \\
\hline Advanced FORM & 0.507 & Not Applicable \\
\hline Monte Carlo & 0.489 & 0.005 \\
\hline
\end{tabular}

\section{DISCUSSION}

Although the advanced FORM result at the design pressure has slight disagreement with the Monte Carlo value of $\mathrm{P}_{\mathrm{f}}$, it is correct to an order of magnitude and therefore serves as a useful estimator for $\mathrm{P}_{\mathrm{f}}$. In addition, the percentage error of the FORM is reduced at higher values of $\mathrm{P}_{\mathrm{f}}$ (for example, at $P=5.4 P_{d}$ the probability of failure computed by FORM is 0.51 and the value computed by Monte Carlo is 0.49), and therefore for most of the fragility curve the FORM gives a reasonably accurate approximation.

\section{SENSITIVITY ANALYIS}

We would like to know which uncertainties make important contributions to our calculated measure of uncertainty, which in this case is the uncertainty in $\mathrm{P}_{\mathrm{f}}$. The uncertainty in $\mathrm{P}_{\mathrm{f}}$ is caused by uncertainty in coefficients of variation of input parameters to the advanced FORM analysis. This type of sensitivity analysis, where parameters are ranked in order of their importance, is known as Factors Prioritisation (FP) (Saltelli, 2008).

A wide variety of methods exist for performing sensitivity analysis, and these methods fall into several broad categories. Sensitivity analysis methods can be local or global, by considering the sensitivity at just one point in the input space or many. In addition the methods can consider the sensitivity to variables on their own or to several variables at a time.

\section{SOBOL INDICES}

One frequently used method of sensitivity analysis is the so called Sobol indices or variance based sensitivity indices. The purpose of Sobol indices is to decompose the variance of the output into variances attributable to each input. Therefore, Sobol indices are a global method of sensitivity analysis. A derivation is available in Sobol (2001).

The Sobol indices are

$S_{i}=\frac{V_{X_{i}}\left[E_{X \sim i}\left(Y \mid X_{i}\right)\right]}{V(Y)}$

for the single input $\mathrm{X}_{\mathrm{i}}$, where $\mathrm{Y}$ is the output of interest. $\mathrm{V}$ and $\mathrm{E}$ represent the variance and expected value, respectively. The total sensitivity indices are given by

$T_{i}=1-\frac{V_{X \sim i}\left[E_{X_{i}}\left(Y \mid X_{\sim i}\right)\right]}{V(Y)}$

which measures the effect of the variable $X_{i}$ including all interactions. The Sobol and Total sensitivity indices can be computed by Monte Carlo simulation. In some cases, for example when the model has too many parameters or the model is very computationally expensive, it is necessary to use a more complex method to compute the Sobol and total sensitivity indices. 
For example, the upper bound of the Total Sensitivity index can be efficiently calculated by integrating the local sensitivity analysis over the whole space of the inputs (Patelli et al, 2010), and the Sobol indices can be efficiently calculated by use of the FAST method given in Tarantola et al. (2006).

\section{METHOD}

The Sobol indices for the sensitivity of $\mathrm{P}_{\mathrm{f}}$, calculated by the advanced FORM method, with respect to the coefficients of variation of each parameter in Table 2 were calculated using OpenCOSSAN. A uniform distribution between 0 and 1 was applied for the coefficients of variation of the input parameters to the advanced FORM, i.e. any value for the coefficients of variation was equally likely, as this is a commonly used uninformative distribution. This assumption is somewhat unjustified as even if the coefficients of variation all fall within this interval there is no reason to assume that each value is equally likely in reality. However, in this case it is a useful approximation as it allows us to study the effect of an arbitrary variation in this parameter. The mean values for the parameters were taken from Table 2.

The analysis was then repeated with $P=5.4 P_{d}$ (chosen for the strength to design load ratio calculated in the previous section in order to make $\left.\mathrm{P}_{\mathrm{f}}=0.5\right)$ and $P=5 P_{d}$. At increased pressures the variance in the Sobol and Total Sensitivity indices computed by Monte Carlo simulation was impracticably high and so it was necessary to compute the Sobol indices using the FAST method (Tarantola et al, 2006) and the upper bound of the Total Sensitivity indices using Patelli's method (Patelli et al, 2010), both of which have been implemented in OpenCOSSAN. This allowed the calculation to be completed in a shorter time as fewer samples were required.

\section{RESULTS}

The calculated Sobol Indices and Total Effects Indices when $P=P_{d}$ are shown in a bar plot in Figure 7 . It is clear that the biggest contributors to uncertainty in the output are the coefficients of variation of $A_{t}$ and $\mathrm{F}_{\mathrm{t}}$. The bar plots show error bars to represent our uncertainty in the Monte Carlo estimators for the indices.

Figures 8 and 9 show the effect of varying $A_{t}$ and $F_{t}$ separately, whilst keeping the other variables fixed at their values from Table 2. There is a sharp increase in failure probability when the coefficient of variation is larger than 0.2. Further analysis shows that the location for this 'knee' in the graph depends upon the value of the other parameters, i.e. if the other coefficients of variation are set as 0.3 then the location of the knee changes to 0.3 . Figure 10 shows the effect of varying both of these parameters simultaneously.

The calculated Sobol Indices and Total Effects Indices upper bounds for $P=5.4 P_{d}$ are shown in a bar plot in Figure 11. It is clear that the biggest contributors to uncertainty in the output are the coefficients of variation of $\mathrm{R}$ and $\mathrm{P}$, followed by $\mathrm{F}_{\mathrm{t}}$ and $\mathrm{A}_{\mathrm{t}}$. Figure 12 shows the effect of varying $\mathrm{P}$ and $\mathrm{R}$ simultaneously when $P=5.4 P_{d}$, whilst keeping the other variables fixed at their values from Table 2 .

The calculated Sobol Indices and Total Effects Indices upper bounds for $P=5 P_{d}$ are shown in a bar plot in Figure 13. Again, it is clear that the biggest contributors to uncertainty in the output are the coefficients of variation of $R$ and $P$, followed by $F_{t}$ and $A_{t}$. Figure 14 shows the effect of varying $P$ and $R$ simultaneously when $P=5 P_{d}$, whilst keeping the other variables fixed at their values from Table 2 . 


\section{DISCUSSION}

The results show a large variability of the failure probability at the design pressure for changing coefficients of variation of $A_{t}$ and $F_{t}$, and this could possibly be explained by the large mean value of these variables. At increased pressures it is clear that the coefficients of variation of $\mathrm{P}$ and $\mathrm{R}$ play a greater role in the variability of $\mathrm{P}_{\mathrm{f}}$.

It is interesting to note that the variability of $\mathrm{P}_{\mathrm{f}}$ is greatly decreased when $P=5.4 P_{d}$, implying that the choice of coefficient of variation is unimportant when $\mathrm{P}_{\mathrm{f}}=0.5$, which justifies the use of the simplified method for when the applied pressure is equal to the strength. Intuitively it is clear that if a distribution is centred on the edge of the failure region (i.e. on the limit state function) then changing the coefficient of variation of the input variables should not significantly move the probability density from the safe region into the failure region.

There is significant variability of $\mathrm{P}_{\mathrm{f}}$ when $P=5 P_{d}$, however the failure probability appears to plateau when the coefficients of variation of $\mathrm{P}$ and $\mathrm{R}$ are above approximately 0.5 . This implies that if there is no data to determine of the Coefficient of Variation then a larger coefficient of variation would be a conservative choice for this pressure. In this context a conservative choice is one which gives an overestimate of $\mathrm{P}_{\mathrm{f}}$. An overestimate is preferable to an underestimate as implying a structure is safer than it is in reality could have severe consequences. However, we also wish for our estimates to be as close as possible to the true value of $P_{f}$ as large overestimates can cause unnecessary over engineering which is undesirable as this can lead to increased costs. The size of coefficient for which this plateau takes place is dependent on mean applied pressure, and this should be considered when attempting to find a conservative value of the coefficients of variation. Moreover, for applied pressures above the strength Figure 14 shows that choosing a lower value of the coefficients of variation would be conservative in this case.

Our analysis appears to justify the choice of coefficients of variation chosen in this work, as the values given in Spencer et al. (2006) and Sundararajan (1995) are less than those chosen here, and hence the assumptions for these parameters in this paper can be considered conservative for applied pressures below the strength.

If engineering judgement can be used to justify the irrelevance of the tails of the fragility curve to the analysis being performed then the impact of using an approximate value of the Coefficient of Variation is lessened, however appropriate conservatism should still be applied.

In future calculations, in order to accurately describe our epistemic uncertainty in these parameters, particularly in the tails of the fragility curve, we should use a more considered approach to uncertainty where possible. For example if a more accurate estimation of the coefficient of variation cannot be obtained it may be necessary to construct a probability box by defining the coefficient of variation as an interval (Ferson, 2003). This approach can be understood as the engineer testing many different values for the coefficient of variation of each variable and choosing the most and least conservative values to give an interval for $\mathrm{P}_{\mathrm{f}}$ (in practice the engineer would use a sophisticated optimisation algorithm coupled with conventional reliability analysis to perform the calculation).

If the coefficients of variation were assumed to be fuzzy variables it would be possible to determine the range of possible values of these coefficients which maintain an acceptably low $\mathrm{P}_{\mathrm{f}}$, with no requirement to repeat the analysis multiple times (Beer, 2011). This presents a significant computational benefit. The acceptable range for $\mathrm{P}_{\mathrm{f}}$ would be specified by the engineer and could be taken from an appropriate design code. Such an approach is known as Factor Mapping (FM), and could be particularly useful for industrial design applications. 


\section{CONCLUSIONS}

First Order Reliability Method (FORM) is applied to predict probability of failure of the containments. Probability of failure vs internal pressure is presented for both types of containments (with and without steel liner). Previous studies undertaken as part of the two international roundrobin exercises have established the ultimate structural collapse mode of the containments under internal pressure loading which indicates that the failure takes place in the general field of the containment wall around mid-height and away from any major structural discontinuities. This is because robust design procedures have been used that provide adequate compensation and local strengthening to avoid structural failure at discontinuities. Based on these experimental studies and the attendant numerical analyses a failure function is presented that assumes first yielding in the hoop direction at mid-height of the cylinder wall. It is shown that when the load term (given by P x mid-radius of the wall) equalises the strength terms (given by crosssectional area/unit height $\mathrm{x}$ yield stress) for rebar, liner, tendon and concrete then the probability of failure of structural collapse of the containment is $50 \%$. The paper presents a simple method to establish structural reliability of a pre-stressed concrete containment which can be useful for probabilistic safety assessment when considering extreme events that lead to over-pressurisation of the containment.

It has been shown that there is a strong dependence of the probability of failure of a concrete containment computed by advanced FORM on the coefficients of variation of the Rebar Yield and Rebar Area at the design pressure. The coefficients of variation of the pressure and radius are also important parameters, especially in the centre of the fragility curve when the applied pressure is increased. The variability of the probability of failure is decreased at this applied pressure; however it is still important to apply conservatism in scenarios where we lack knowledge of the true value of these parameters. This illustrates the importance of ensuring that the choice of these parameters is justified by evidence from real models, as a failure to choose an appropriate value could result in an order of magnitude error on the probability of failure at the design pressure. However, less caution is required when we simply wish to find the pressure at which $\mathrm{P}_{\mathrm{f}}=0.5$.

\section{REFERENCES}

Au, S.K. and Beck J.L. (2001). "Estimation of small failure probabilities in high dimensions by Subset Simulation". Probabilistic Engineering Mechanics 16.4: 263-277.

Beer, M. et al. (2011). "Structural reliability assessment with fuzzy probabilities". Proceeding of ISIPTA.

Ferson, Scott, et al. (2003). "Constructing probability boxes and Dempster-Shafer structures". Sandia National Laboratories: 143-180.

Kamatam, K and Prinja N.K. (2011). "Analysis of the BARC Containment Model", Transactions SMiRT 21, New Delhi, India, Paper 820.

Patelli, E, Pradlwarter, H.J. and Schuëller, G.I. (2010). "Global sensitivity of structural variability by random sampling”. Computer Physics Communications 181.12: 2072-2081.

Patelli, E. (2016). "COSSAN: A Multidisciplinary Software Suite for Uncertainty Quantification and Risk Management". Handbook of Uncertainty Quantification. Ed. by Roger Ghanem, David Higdon, and Houman Owhadi. Cham: Springer International Publishing, pp. 1-69.

Patelli, E., et al. (2014). "OpenCossan: An efficient open tool for dealing with epistemic and aleatory uncertainties". Vulnerability, Uncertainty, and Risk: Quantification, Mitigation, and Management. ASCE. 
Prinja, N.K. and Shepherd, D. (2003). "Numerical Simulation of Limit Load Testing of $1 / 4$ Scale Prestressed Concrete Containment Vessel, Pressure Equipment Technology - Theory and Practice", Professional Engineering Publishing Limited.

Rackwitz, R. (1976). "Principles and methods for a practical probabilistic approach to structural safety", Sub-committee for First Order Reliability Concepts for Design Codes of the Joint CEB-CECM-CIB-FIPIABSE Committee on Structural Safety, CEB Bulletin N112.

Saltelli, A., et al. (2008). "Global sensitivity analysis: the primer". John Wiley \& Sons.

Schuëller, G.I, and Stix, R. (1987). "A critical appraisal of methods to determine failure probabilities". Structural Safety 4.4: 293-309.

Sobol, I.M. (2001). "Global sensitivity indices for nonlinear mathematical models and their Monte Carlo estimates". Mathematics and computers in simulation 55.1: 271-280.

Spencer, B. W., Petti, J. P. and Kunsman, D. M. (2006). "Risk-informed assessment of degraded containment vessels". Sandia National Laboratories, Albuquerque, NM.

Sundararajan, C. R. (1995). "Probabilistic structural mechanics handbook: theory and industrial applications". Chapman \& Hall.

Tarantola, S, Gatelli, D. and Mara, T.A. (2006). "Random balance designs for the estimation of first order global sensitivity indices". Reliability Engineering \& System Safety 91.6: 717-727.

\section{ABBREVIATIONS}

BARCOM Bhabha Atomic Research Centre (BARC) Containment test model

$\mathrm{CoV} \quad$ Coefficient of Variation

FEA Finite Element Analysis

FORM First Order Reliability Method

PCCV Pre-stressed Concrete Containment Vessel

SNL Sandia National Laboratories 


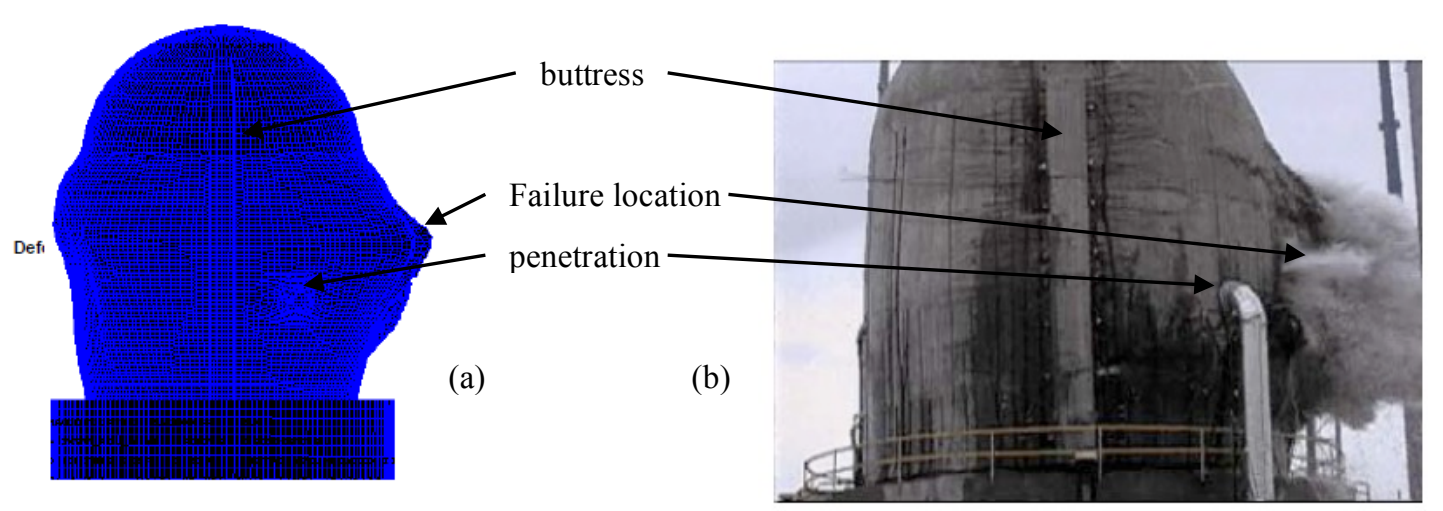

Figure 1. Predicted failure mode of the SNL model (a) FEA results vs (b) test at $\mathrm{P}=3.65 \mathrm{Pd}$

(Figure in colour please) 


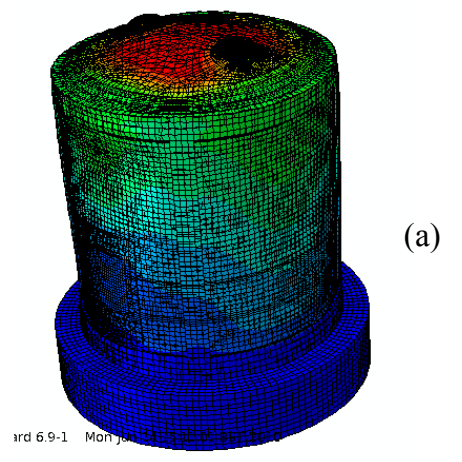

(b)

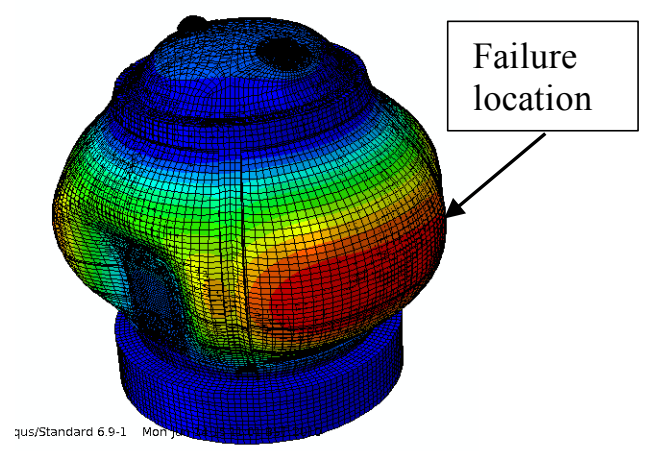

Figure 2. Predicted response of the BARC model (a) under prestress only and (b) at $\mathrm{P}=2.89 \mathrm{Pd}$ (Figure in colour please) 


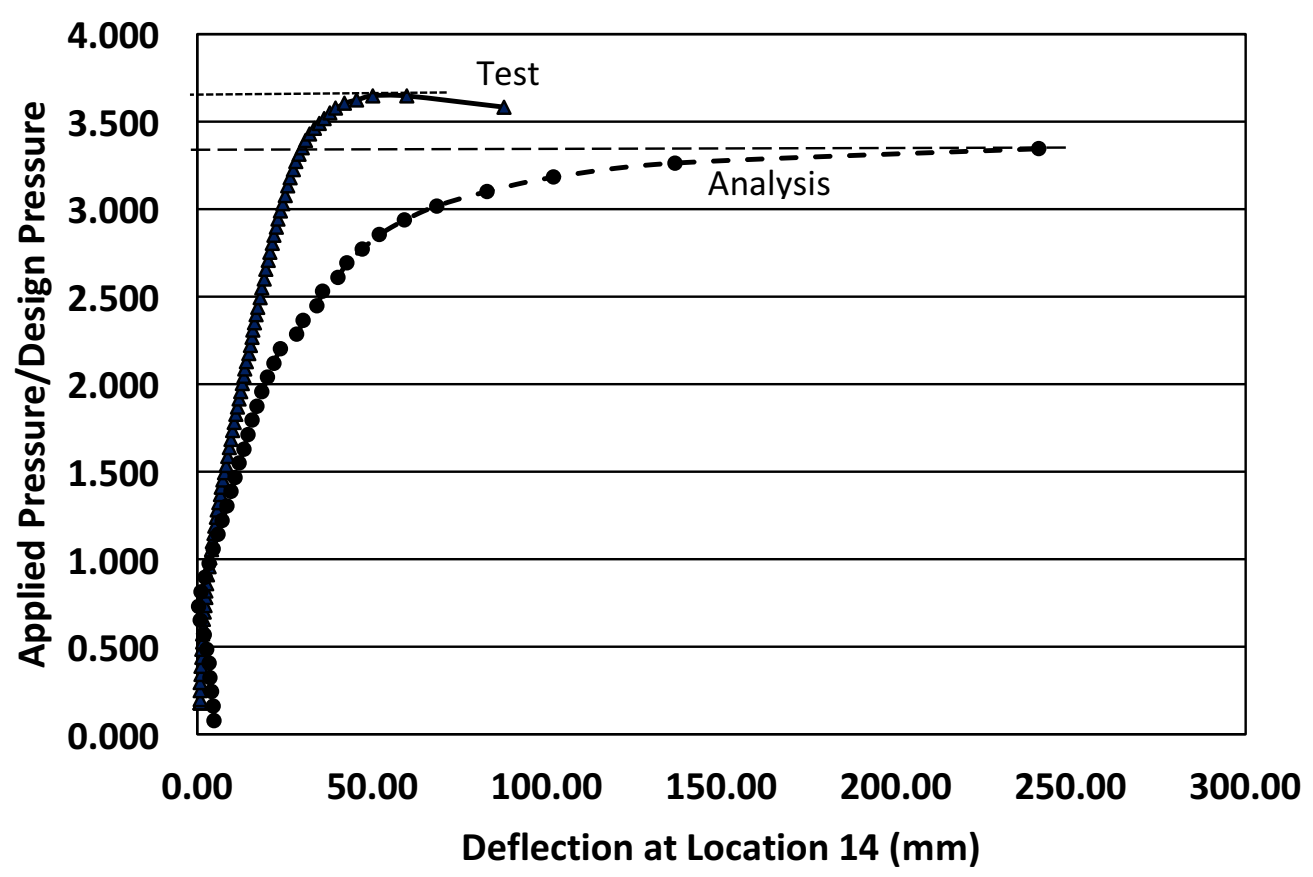

Figure 3. SNL test vs analysis comparison of deflection near failure location 


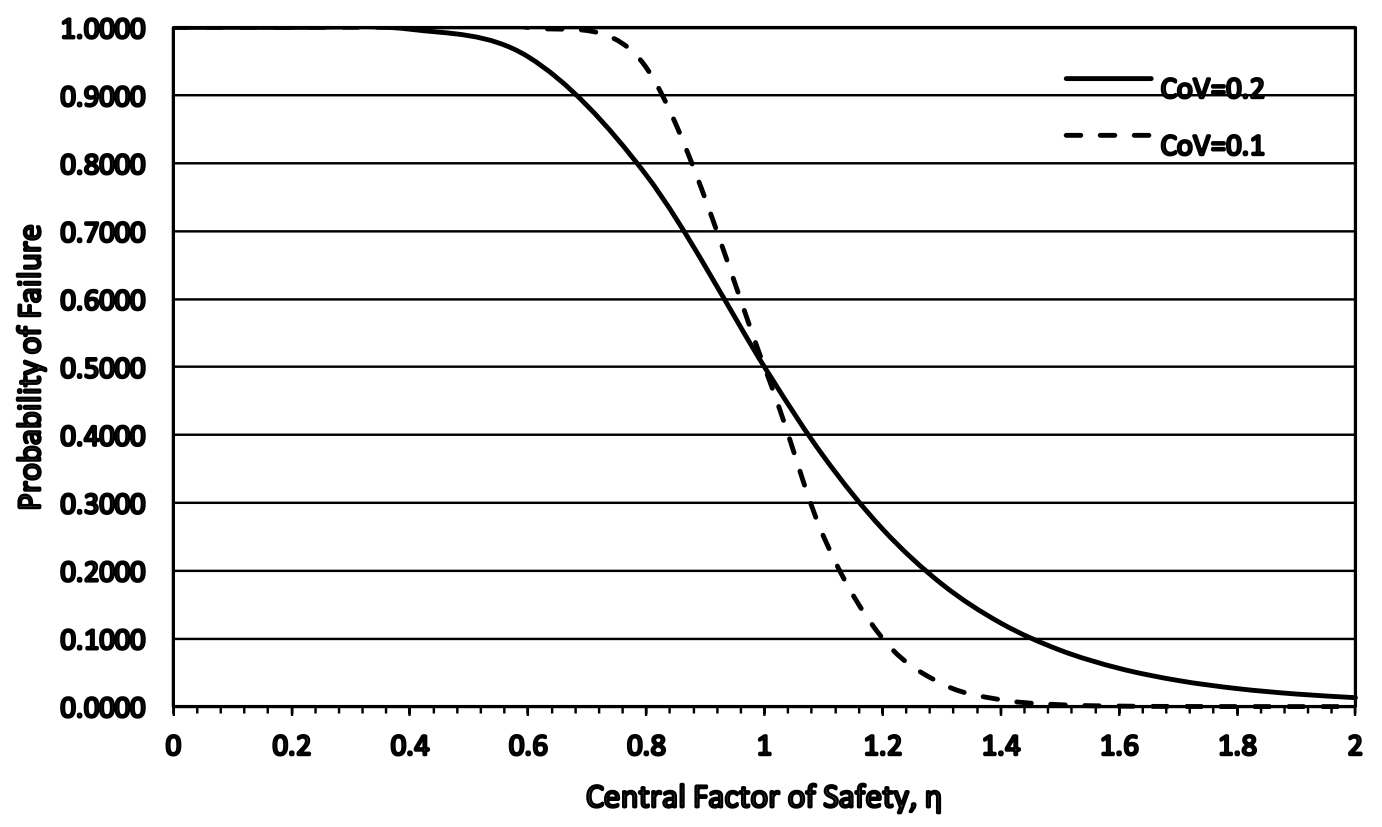

Figure 4. Probability of failure vs Central Factor of Safety 


$$
\text { S }
$$




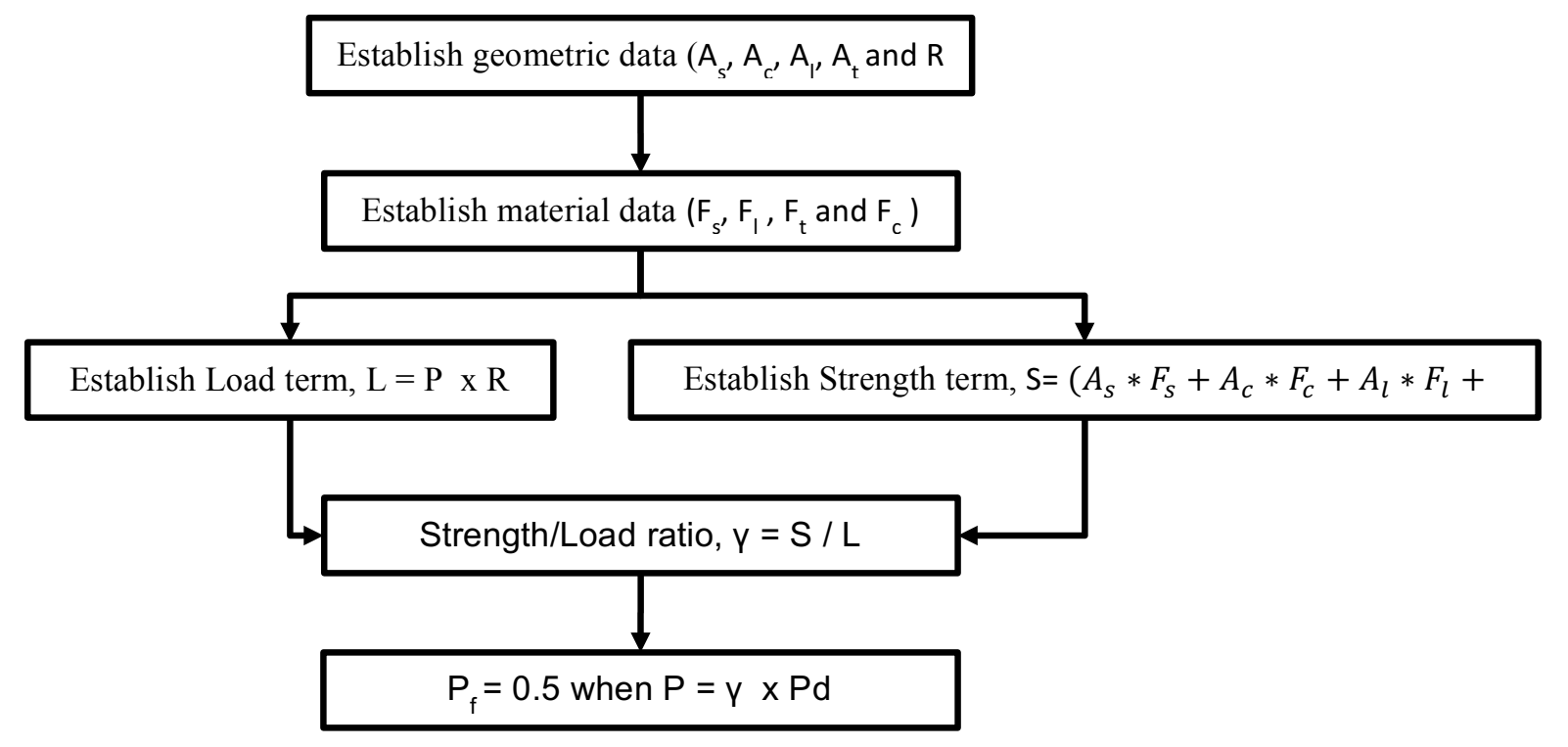

Figure 6. Simplified method to establish $\mathrm{P}_{\mathrm{f}}$ of concrete containment 


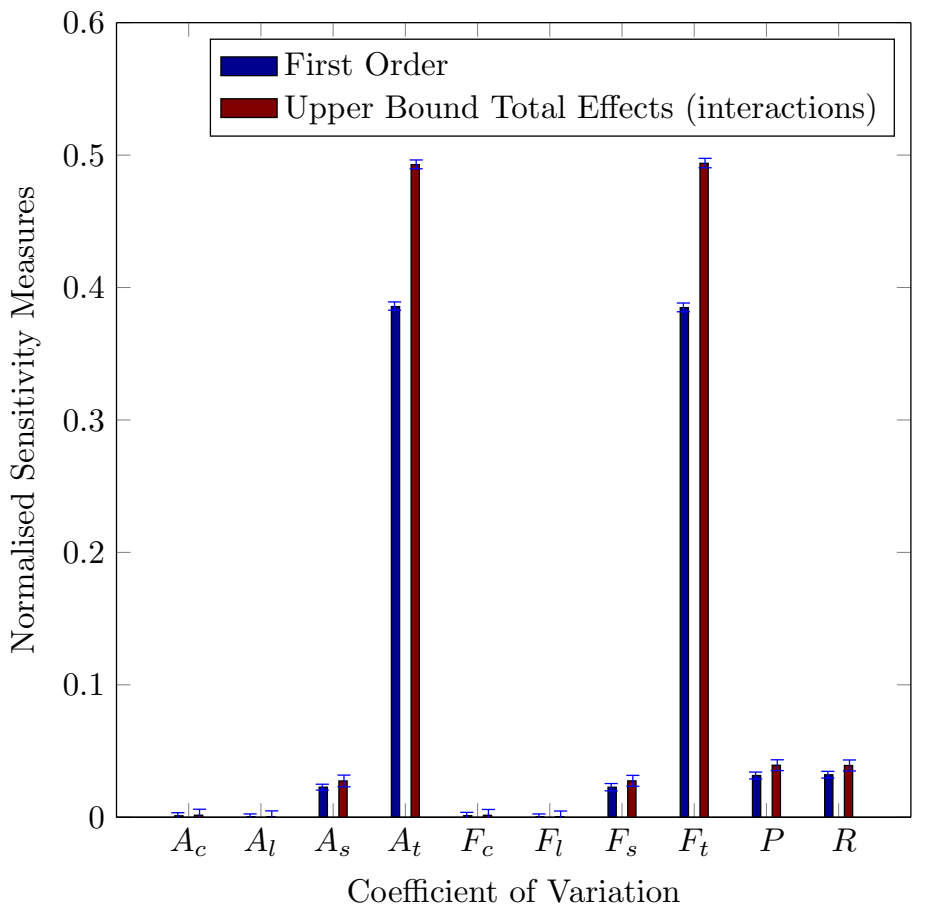

Figure 7. Plot of Sobol Indices and Total Sensitivity Indices for uncertain coefficient of variation for all input parameters to advanced FORM at $\mathrm{P}=P_{d}$. The error bars represent one standard deviation.

(Figure in colour please) 


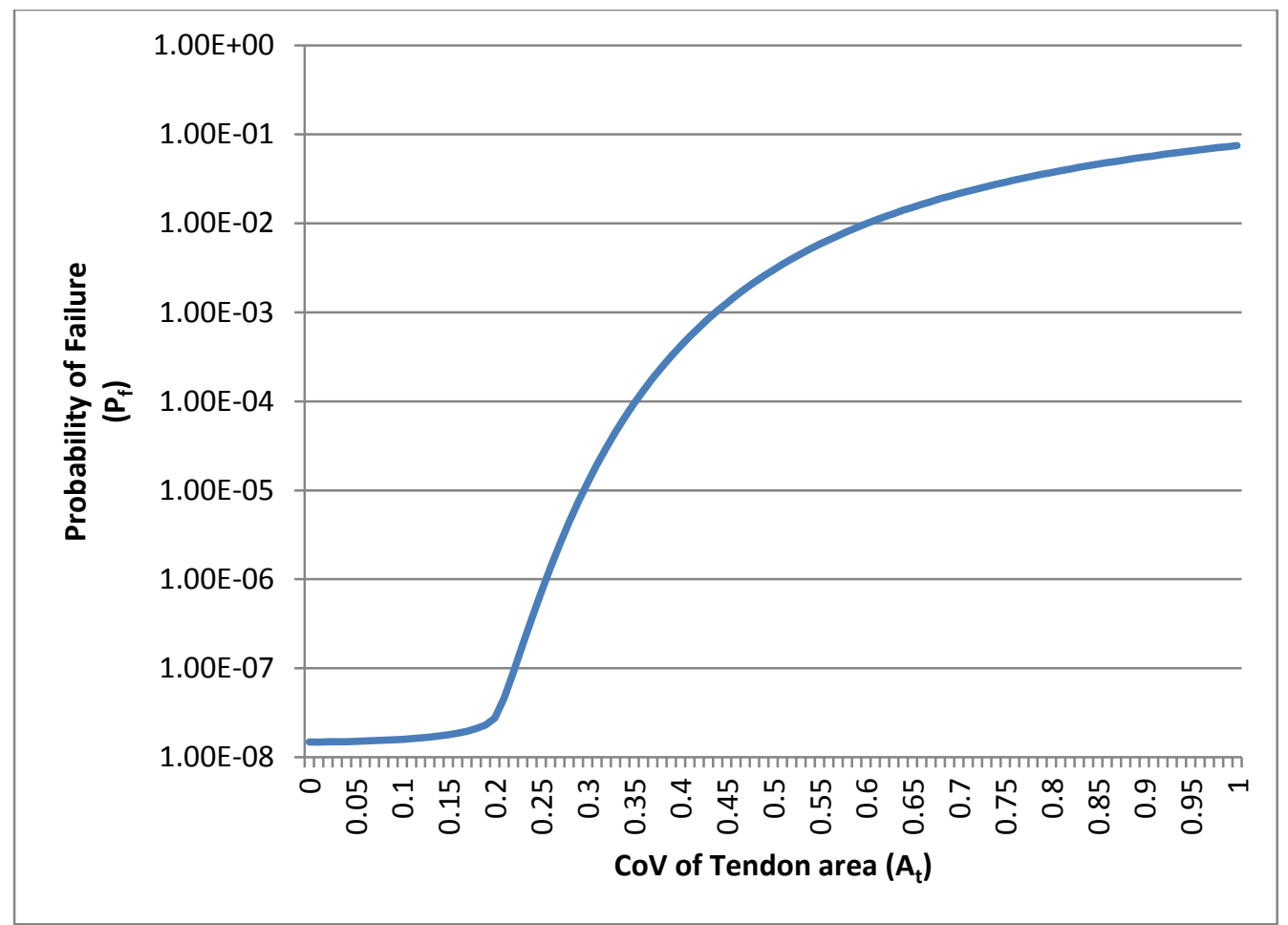

Figure 8. Plot of failure probability at $P=P_{d}$ for varying coefficient of variation of tendon area, $\mathrm{A}_{\mathrm{t}}$, while keeping other variables fixed. 


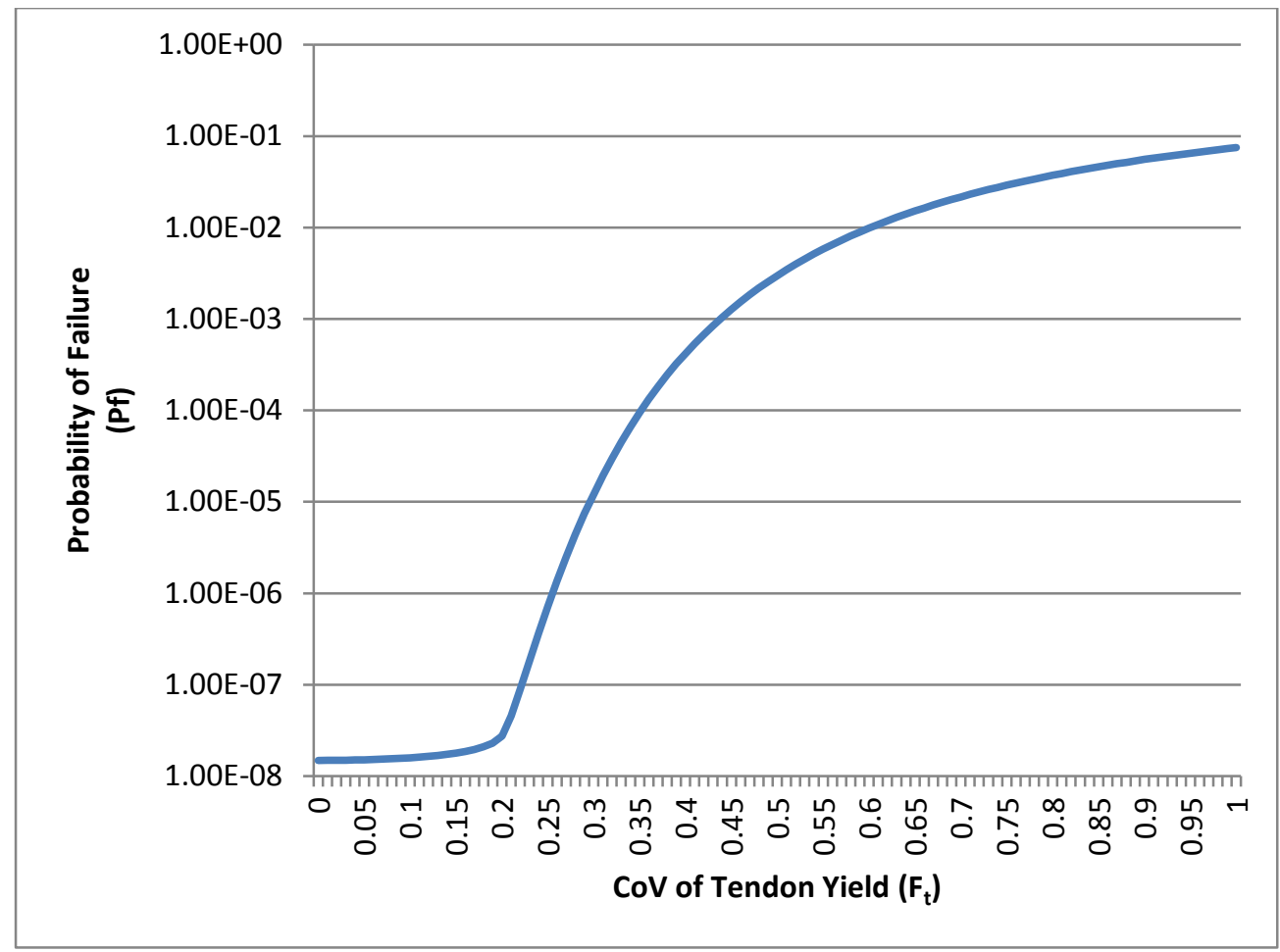

Figure 9. Plot of failure probability at $P=P_{d}$ for varying coefficient of variation of tendon yield, $\mathrm{F}_{\mathrm{t}}$, while keeping other variables fixed. 


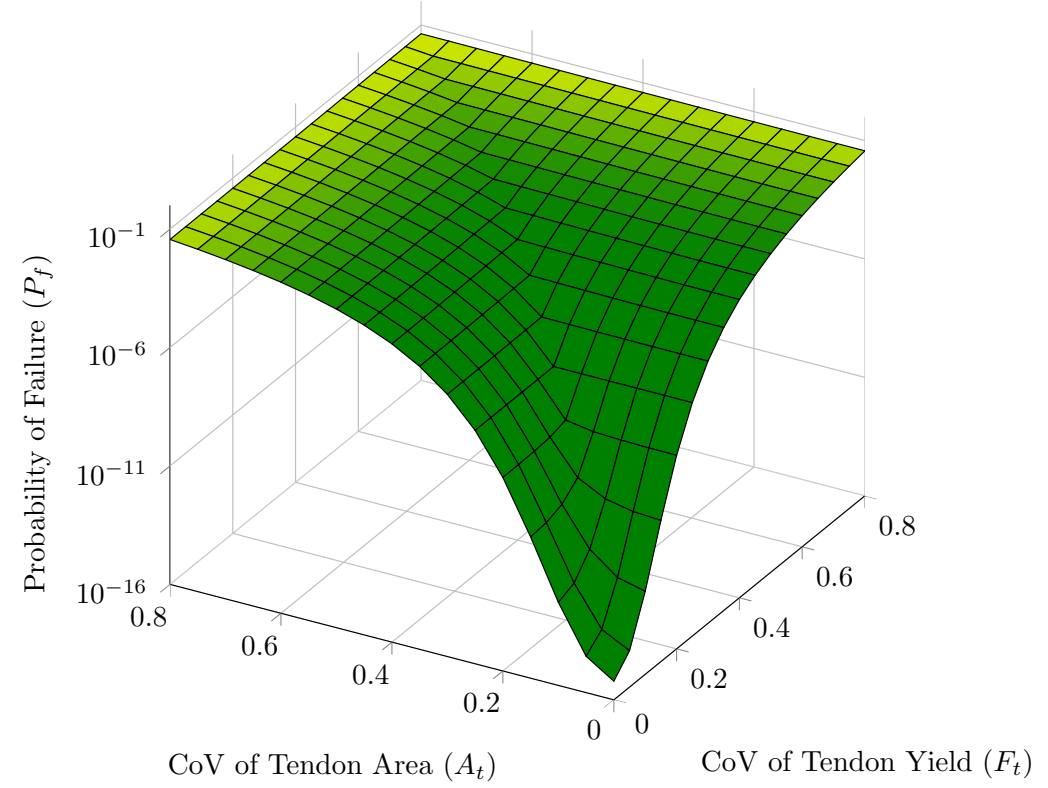

Figure 10. Plot of failure probability at $P=P_{d}$ for varying coefficient of variation of tendon yield, $\mathrm{F}_{\mathrm{t}}$, and tendon area, $A_{t}$, while keeping other variables fixed. 


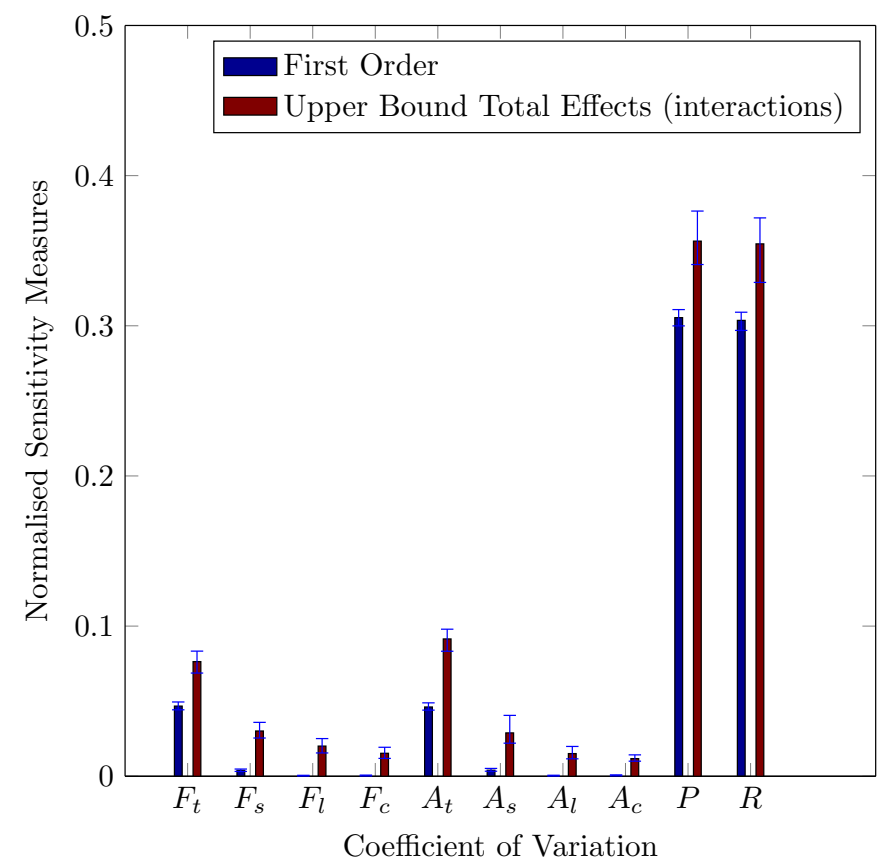

Figure 11. Plot of Sobol Indices and Total Sensitivity (upper bound) Indices for uncertain coefficient of variation for input parameters to advanced FORM at $\mathrm{P}=5.4 P_{d}$. In this figure the error bars represent the 5\%-95\% confidence interval. 


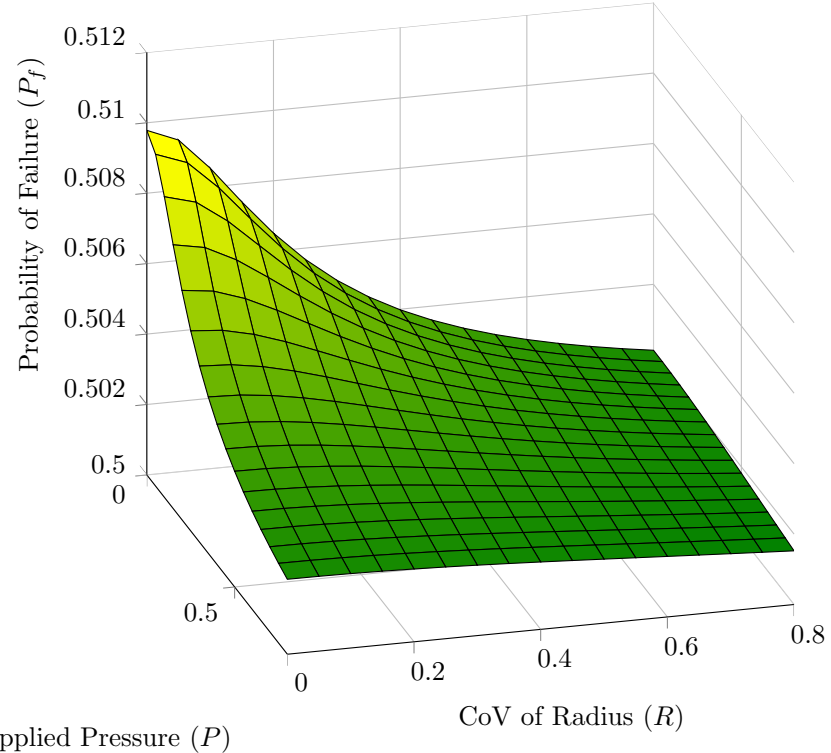

Figure 12. Plot of failure probability at $\mathrm{P}=5.4 P_{d}$ for varying coefficient of variation of applied pressure, $P$, and radius, $R$, while keeping other variables fixed. 


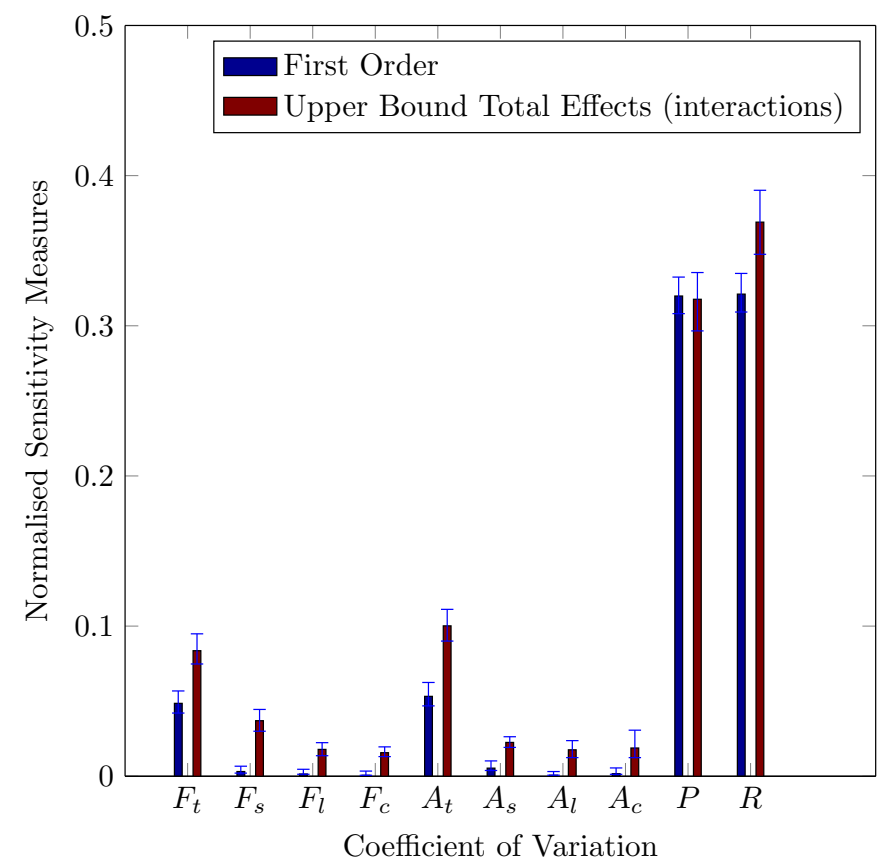

Figure 13. Plot of Sobol Indices and Total Sensitivity (upper bound) Indices for uncertain coefficient of variation for input parameters to advanced FORM at $\mathrm{P}=5 P_{d}$. In this figure the error bars represent the $5 \%-95 \%$ confidence interval. 


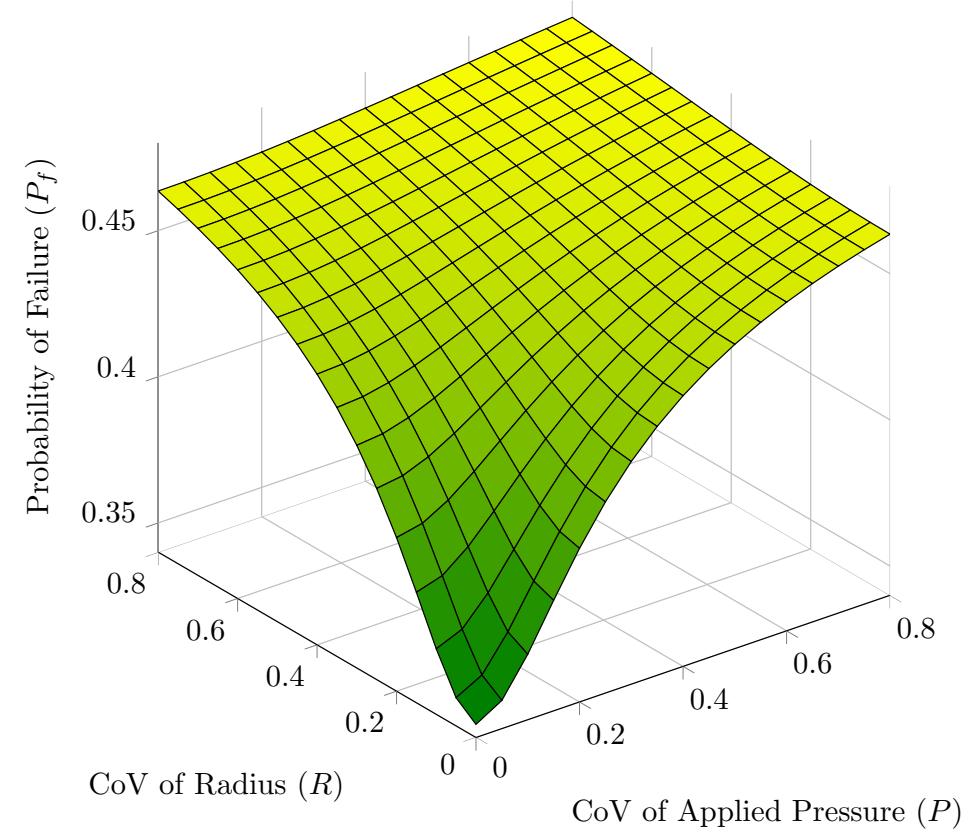

Figure 14. Plot of failure probability at $\mathrm{P}=5 P_{d}$ for varying coefficient of variation of applied pressure, $\mathrm{P}$, and radius, $\mathrm{R}$, while keeping other variables fixed. 